\title{
Tree Risk Evaluation Environment for Failure and Limb Loss (TREEFALL): An integrated model for quantifying the risk of tree failure from local to regional scales
}

\author{
Gullick, D ${ }^{\mathrm{a}, \mathrm{b}}$, Blackburn, G, A ${ }^{\mathrm{a}}$, Whyatt, J D $\mathrm{D}^{\mathrm{a}}$, Vopenka, Pa , Murray, Ja \\ Abbatt, $\mathrm{J}^{\mathrm{a}}$ \\ ${ }^{a}$ Lancaster Environment Centre, Library Avenue, Lancaster University, Lancaster LA1 \\ $4 Y Q, U K$ \\ ${ }^{b}$ Corresponding Author: Email: d.gullick@lancaster.ac.uk
}

\section{Abstract}

Trees provide a multitude of ecosystem services but are vulnerable to failure and limb loss under high winds. This is a natural process which initiates regeneration in forests but tree failures close to critical infrastructure networks lead to disruption to services and financial loss. Hence, network operators tend to apply the precautionary principle and remove all trees close to such infrastructure which leads to unnecessary loss of healthy trees, therefore, a more focussed approach is required. We introduce TREEFALL: an objective and scalable framework to assess tree failure risk. It builds upon well-established models to quantify tree geometry, downscale wind parameters, simulate shielding by neighbouring trees and calculate wind-induced failure risk based on meteorological data for previous storms, scenarios or forecasts. Consequently, TREEFALL can identify individual trees which pose the greatest threat to infrastructure networks which can be targeted for field survey and management interventions where necessary. The model has broad potential for application to many different types of infrastructure networks 
and across the forest and environmental sciences.

Keywords: Tree failure, Wind-throw, Model Framework, Integrated assessment, Critical Infrastructure Support, Decision support

\section{Software Availability}

The simulation software introduced here is Tree Risk Evaluation Environment for Failure and Limb Loss (TREEFALL), which can be seen at https: //lec-treefall.lancs.ac.uk. TREEFALL is a software package written primarily in Java, utilising the Postgres (https://www.postgresql.org/) database engine with the PostGIS extension (http://postgis.net/), Hibernate (http: //hibernate.org/) and the Flowstar tool within the Atmospheric Dispersion Modelling System (ADMS) Urban Package (http://www.cerc. co.uk/environmental-software/ADMS-Urban-model .html). The model interface and outputs are visible via a web browser using the webserver technology Apache TomCat (https : //tomcat . apache org/) and GeoServer (http: //geoserver.org/). The datasets used within this model can be obtained from the MetOffice (http: //www .metoffice.gov.uk), Ordnance Survey (OS) (https://www.ordnancesurvey.co.uk/), Centre for Ecology and Hydrology (CEH) (https : //www. ceh.ac.uk/services/land-cover-map-2007) and BlueSky (https://www.blueskymapshop.com/products/national-tree-map).

\section{Introduction \& background}

High wind events are one of the primary causes of tree failure [10]. For example, storm Klaus in 2009 resulted in the windthrow of an estimated $2340 \mathrm{~km}^{2}$ of forest across Europe [5], and given the widely reported effects 
of climate change it has been argued that even stronger wind storms are expected in the future [6]. In order to assess the impacts of wind storm events and develop appropriate management strategies effective tree failure models are required. There are a number of existing models of tree failure: HWIND [17], GALES [7], FOREOLE [1], iLand [25] and Geographic Information System (GIS) based techniques [34], amongst others (as compared and discussed by Gardiner et al. [8]). Many of the aforementioned techniques treat a stand of trees or a cell in a grid as the unit of evaluation [18] as the primary focus is commonly harvestable timber loss. However, the losses experienced in the case of tree failure can extend beyond the monetary value of the timber to the disruption of a wide range of environmental processes and the ecosystem services that are associated with trees.

Moreover, tree failures within proximity to critical infrastructure (such as overhead power lines, railways or roads) pose a risk of damage to that infrastructure and disruption to associated services. The operators of infrastructure networks are impacted financially in the case of tree failure events. Direct costs are incurred through the removal of the failed tree and the repair of any damage caused to the infrastructure. Indirect costs are also incurred by the infrastructure provider, typically in the form of fines and increased compensation claims from the general public for infrastructure downtime. In the UK the main power network operators are privately operated companies which are overseen by a government-backed regulatory authority called the Office of Gas and Electricity Markets (Ofgem). The power companies must adhere to strict requirements for infrastructure resilience outlined by Ofgem. In the event that these requirements are not met, the network operators face 
fines on top of repair costs. Similar regulations apply to other infrastructure networks.

To avoid such costs, infrastructure providers focus substantial effort on tree maintenance. This involves continuous manual risk assessment and proactive tree removal along the length of the network. However, as these infrastructure networks expand to accommodate the increasing population, it is becoming apparent that traditional approaches alone, such as employing experienced tree surveyors, are costly, subjective and impractical for the continued assessment and monitoring of such large numbers of trees [16]. As a result, infrastructure providers are looking towards technology and modelling to help concentrate their efforts in key areas. This problem is unique in that infrastructure is the focus, rather than the timber from the trees themselves. In contrast to many of the models previously mentioned, this means that using a stand of trees as the unit of analysis is not appropriate. Many trees within a stand (especially in the middle) are physically too far away from infrastructure to cause damage if they fall, whereas trees near the edge of the stand are more likely to be within proximity of critical infrastructure. Similarly, the effect of wind upon the trees varies throughout the canopy. With this uneven distribution of risk throughout the stand, a more apt unit of assessment would be a single tree; the lack of such refined focus has been argued as a weakness of some existing models [9].

With a focus on individual trees, a model requires a deeper understanding of tree bio-mechanics. Fortunately, scientists have developed a large body of literature focused on understanding this area. Trees can be modelled as engineered and mechanistic structures with equations and terms describing 
their reactions to certain conditions. Assessments can be carried out in multiple ways: from visual assessments $[15,12,22]$ that focus on general factors (size, structure, vigor, and lean), to specialist testing of decay [30, 23, 28, 29], or even static-load tests which measure the force required to pull down a tree $[32,31,27]$. Despite the richness of the available literature, and the techniques described within, it still seems that "arborists [tree surveyors] apply a small set of experimental data to assess and evaluate a large, diverse and complex tree population" [14]. Indeed, these bio-mechanical formulae for the reaction of trees in certain scenarios are context specific, and there is little in the way of guidance on how to determine a critical threshold for tree failure, or confirmation that any formula accurately describes the reaction of a tree outside of its specific context [14].

The effect of this on the professional world is that the assessment of tree health and stability is carried out by trained surveyors using a set of subjective metrics. Quantifying this kind of complex and multifaceted problem is inherently difficult: whichever way the underlying problem is tackled and modelled, there are always more variables or specific contexts which could affect the outcome. Table 1 shows a non-exhaustive list of elements that are influential in tree failure, a selection of which would be assessed by any experienced surveyor. Whilst the more obvious causes such as wind damage, or poor health are outlined, there are numerous other factors. One or more of these may contribute to failure in any given scenario. In the context of social science, Rittel and Webber [21] describe this type of problem as Wicked: a problem that is difficult or impossible to solve because of incomplete, contradictory, and changing requirements that are often difficult to recognize 
- all qualities that can be applied to tree failure prediction. This Wicked nature is arguably the reason that tree risk inspection is not yet automated; a surveyors experience and training allows them to assess the risk of a tree taking into account many more factors than are reasonably detectable using current technology. Individual tree inspection by trained personnel is expensive, subjective, and impractical on very large scales, but irreplaceable given the complexity of the task. 
Table 1: A selection of the factors that a skilled tree surveyor may use to assess a trees resilience to failure.

\begin{tabular}{|c|c|}
\hline Category & Description \\
\hline Structure & $\begin{array}{l}\text { Crown, stem, basal, root architecture, stress adaptations (burrs, } \\
\text { bulges, cracks, ribs), structural plasticity (species specific), failure } \\
\text { history, age relevant and species specific features }\end{array}$ \\
\hline $\begin{array}{l}\text { Abiotic } \\
\text { Factors }\end{array}$ & $\begin{array}{l}\text { Solar and water availability, prevailing wind (loading, sail area, dis- } \\
\text { persion), location, recent site disturbance, soil chemistry/pollution, } \\
\text { ambient temperature, } \mathrm{O}_{2} \text { and } \mathrm{CO}_{2} \text { levels }\end{array}$ \\
\hline $\begin{array}{l}\text { Biotic } \\
\text { Factors }\end{array}$ & $\begin{array}{l}\text { Pests, disease and pathogens, wildlife and human damage, produ- } \\
\text { cer, consumer, decomposer equilibrium }\end{array}$ \\
\hline $\begin{array}{l}\text { Roots } \\
\text { and Soil }\end{array}$ & $\begin{array}{l}\text { Anchorage, nutrient and water provision, symbiotic (fungal) rela- } \\
\text { tionships, disturbance history }\end{array}$ \\
\hline $\begin{array}{l}\text { Visual } \\
\text { Symp- } \\
\text { toms }\end{array}$ & $\begin{array}{l}\text { Decay cavities, evidence of structural strength loss, exudates, die- } \\
\text { back, crown retrenchment, improper wound occlusion, unseasonal } \\
\text { foliar loss, excessive dead wood, excessive epicormic growth, pres- } \\
\text { ence of foreign bodies, bark slough, poor growth, reduced vigour }\end{array}$ \\
\hline
\end{tabular}


The model developed in the present study is the Tree Risk Evaluation Environment for Failure and Limb Loss (TREEFALL). TREEFALL uses readily available information on trees and their environmental context in order to identify individual trees that pose the most risk due to their position in relation to infrastructure and their aerodynamic context. This allows the prioritisation of these trees in field surveys to acquire information on the full range of factors which influence tree failure in order to inform subsequent management interventions.

\section{The Model: TREEFALL Overview}

TREEFALL exists as a software framework that collects relevant data from multiple sources and supplies these to various implemented models to calculate risk values for every tree. An overview process diagram of TREEFALL is shown in Figure 1. 


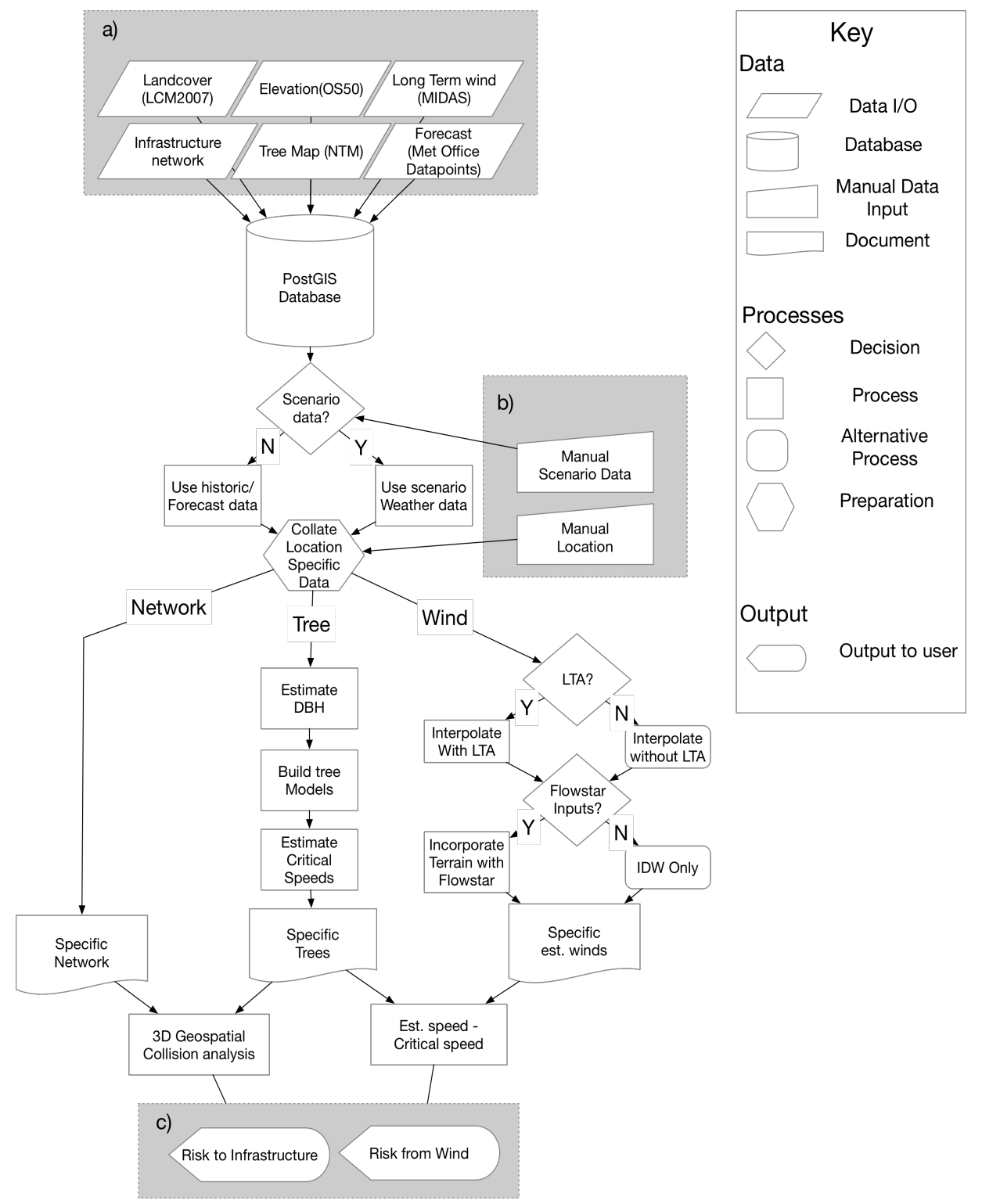

Figure 1: A process diagram for TREEFALL. Input datasets (a) are collected in to a PostGIS database. Manual inputs (b) of optional weather scenarios and site of interest location are used to collate location specific data from the database and user options. This dataset feeds into wind analysis which interpolates given wind data to estimate wind speeds around the site of interest, tree analysis which estimates tree properties and the critical wind speed required to cause failure, and network analysis. Critical wind speed for the tree is compared to estimated wind speed as an estimate of risk from wind, and 3D collision detection is performed between trees and infrastructure network to determine risk to infrastructure. These two values are reported to the user (c). 
Figure 1 shows a process diagram for TREEFALL. Input datasets (a) are collected in to a PostGIS database. Data collected can be conceptualised as existing within one of three categories. Firstly, data pertaining to tree calculations, including individual tree geometry and within canopy mechanisms which consist of: tree locations, heights and crown areas as described within the National Tree Map (NTM) dataset provided by our project partner BlueSky. Secondly, data pertaining to wind calculations and its intelligent down scaling which consist of: long-term wind averages available from the Met Office Integrated Data Archive System (MIDAS); observed and predicted weather data collected daily from over 200 Met Office weather stations across the UK; a Digital Terrain Map (DTM) of the UK at $50 \mathrm{~m}$ spatial resolution; and a Land Cover Map (LCM) for the same area at 20m spatial resolution. Finally, a dataset describing the spatial characteristics of the infrastructure for which to calculate risk, which can be lines, points or polygon features easily exported from any GIS.

Manual inputs (b) of optional weather scenarios and site of interest location are used to collate location specific data from the database and user options. This allows a user to specify areas to study and to either look at historical data, or if supplied, manual weather data as a scenario.

This dataset feeds into three streams of process which are discussed in detail in sections 2.1, 2.3 and 2.4. The tree analysis module processes the supplied data to estimate tree properties and uses these properties to calculate a 'critical wind speed' - the speed at which the tree is estimated to fail. The wind analysis module uses supplied data to estimate the actual windspeed in the given scenario or historical data event. The series of processing 
techniques adjust such that they are appropriate for the datasets are available. Where Long Term Average (LTA) data are supplied it is incorporated into the first stage of wind interpolation for improved accuracy. Where landcover and elevation data are available, third party software (FLOWSTAR) is used to help interpolate wind speeds incorporating the effects of terrain. From here estimated windspeed atop each tree is compared to its estimated critical wind speed to give a value for risk from wind. A 3D geospatial collision function evaluates each trees ability to damage nearby infrastructure in the case of failure, a value for the risk to infrastructure. These two values are reported to the user (c) for each tree in the form of an explorable map.

This evaluation environment is intended to operate both as an early warning forecast in case of predicted extreme weather events, and as a scenario testing tool in which users can run historic or synthetic storm events to learn what effects they may have on the infrastructure in question. As such, much of the weather data is collected automatically and appropriate calculations automatically performed as new data becomes available, and the landcover and elevation are largely static (or require very infrequent updates). The infrastructure network and tree map data requires manual updates as the user feel appropriate.

TREEFALL has a modular design which allows flexibility in inputs depending on the availability of data for specific study sites. Based on the characteristics of the input data, different analytic modules are used within the system. For example, the UK NTM dataset has been derived through aerial photogrammetry. We acknowledge that this is a unique dataset and equivalent datasets may not be available in other countries. In this case, 
tree data created from Light, Detection and Ranging (LiDAR) can be substituted. Other datasets, such as LTA wind speed are used to improve accuracy of weather interpolation techniques but can be omitted if the data is not Available.

Whilst this problem is seemingly complex in nature, this framework distils this problem into a series of questions for each tree which can be answered in turn: 'What critical speed of wind is estimated to cause failure for this tree? What is the estimated wind speed at each trees location? Is the estimated wind speed greater than the critical wind speed? If so, can this tree cause damage to nearby infrastructure?' The following subsections explain how each of these questions can be answered by discussing how each of the key modules within TREEFALL operate in detail.

\subsection{Step 1: Individual Tree Geometry}

The next two sections describe how the framework answers the question 'What critical speed of wind is estimated to cause failure for this tree?' As discussed earlier, individual trees rather than stands are modelled in TREEFALL. For the very large numbers of trees that may surround an infrastructure network, detailed measurements of each tree are difficult to collect and maintain. Therefore, for tree information TREEFALL utilises the NTM dataset, which includes tree location, tree height and tree crown radius, which allows the positioning of trees within the model and the estimation of other tree properties. From these few parameters, an idealised tree can be modelled.

Bonnor [4] shows that an equation in the following form can be used for estimating stem diameter from measurements of height and crown size. 


$$
D=\left(a+b_{1} H+b_{2} W+b_{3} H W\right)
$$

where

$D=$ stem diameter at breast height $(1.3 \mathrm{~m})$,

$H=$ tree height and

$W=$ tree crown width

Following Bonnor's format, a study was performed on a representative mixed woodland in north west England. Throughout this woodland 60 trees were randomly selected and their height, crown diameter and diameter at 1.3 meters from the ground. The analysis extent is influenced by standard forestry measurement conventions [33]. This selection consisted 40 deciduous trees, primarily Oak and Ash, and 20 coniferous trees, mostly Scot's Pine and Yew trees. The data collected allowed a regression formula in the above format to be generated where $a=-11.568, b_{1}=1.050, b_{2}=5.561$ and $b_{3}$ $=-0.046$. Unlike Bonnor's original work, $D$ in this study is in centimetres, and $H$ and $W$ measured in meters. The $R^{2}$ and RMSE are 0.88 and 9.4 respectively.

Given the NTM estimated height and width, and the calculated Diameter at Breast Height (DBH) it is now possible to approximate and model each tree. In this model trees are considered generic in form: little is known about the species or health of each tree as can be expected at this scale. Instead, TREEFALL considers an idealised tree shape, as shown in Figure 2. This shows a trunk (dimensions based upon DBH supporting a semi-porous 
sphere (representing the canopy), the dimensions of which are based upon the height $(H)$ and crown radius $(R)$ of the tree described within the NTM dataset. This model tree is positioned spatially as described in the NTM dataset, shown as $(X, Y, Z)$

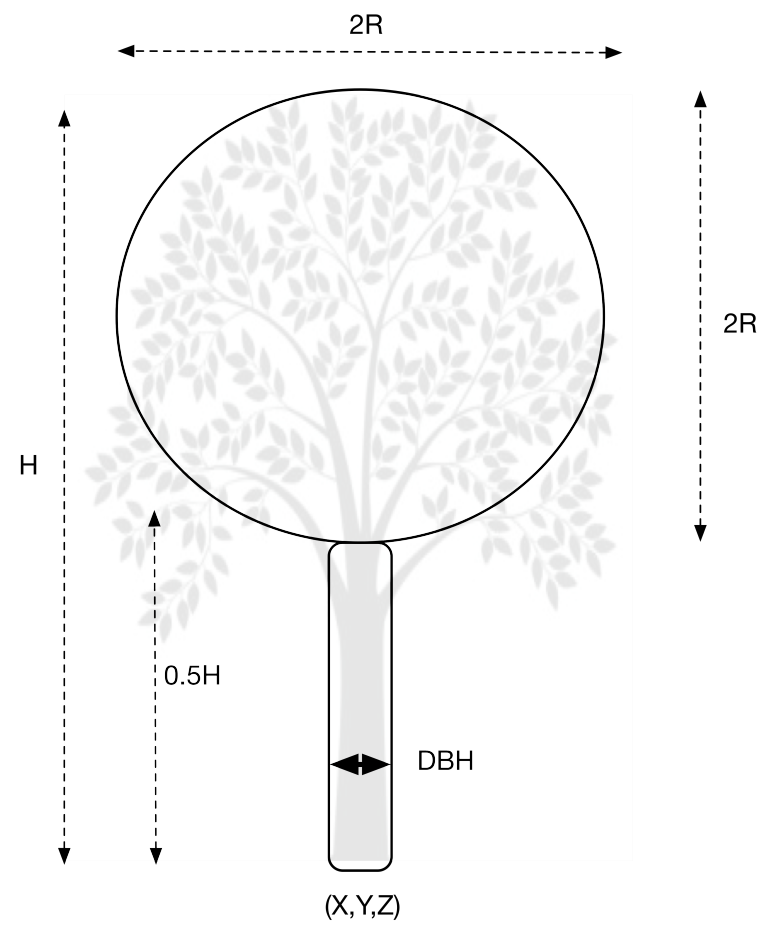

Figure 2: A model Tree. The simplified tree shape is a function of height $(\mathrm{H})$ crown radius (R) and DBH.

This idealised tree model is used as a basis for deriving tree parameters in the following sections - specifically frontal area index for the drag partition model of Raupach [20, eq.1] (discussed in Section 2.2) and values for modulus of rupture, wood density and biomass described by Seidl et al. [26, eqs.9, 12 and 14]. Where individual tree species is known, appropriate values can 
be used within this calculation. Although these values are species specific, the most variation between deciduous and coniferous trees. Where possible, landcover data is used to determine properties of the woodland; coniferous or broadleaf woodland for example. This data is used to estimate appropriate population percentages tree species to be used in the model. When no, or limited, species data are available, representative populations are imagined for a typical British woodland. This representation is region specific and would need amending if used elsewhere.

\subsection{Step 2: Calculating the Critical wind Speed}

Critical wind speeds to cause failure are calculated by providing parameters to the functions described within Seidl et al. [26] based upon the individual tree models described above and their spatial distribution. Primarily, functions for turning coefficient (seen as $T_{c}$ ), critical uprooting wind speed (seen as cws uprooting), and critical stem breakage wind speeds (seen as cws breakage) ( equations 9, 12 and 14 in [26] respectively) are populated for each tree. These functions estimate possible wind speeds that result in uprooting or stem breakage given the physical dimensions of the tree based upon empirical measurement. Importantly for this work, these functions consider more than the individual tree geometry. The location within the stand is incorporated through the inclusion of the Hegyi competition index $\left(C_{\text {Hegyi }}\right.$, the distance-dependent competition index by Hegyi [11]) and gap factor $\left(f_{\text {gap }}\right.$, the factor representing the gap between each tree and other trees upwind) that may be shielding each tree from oncoming wind. Within TREEFALL $C_{\text {Hegyi }}$ is calculated as outlined in [11] using trees within a $3.05 \mathrm{~m}$ (10 feet) radius of each tree as potential neighbours. As the gap factor is inherently 
dependant on wind direction, TREEFALL pre-calculates this for multiple directions as a 'gaprose'. Figure 3 illustrates how the area surrounding each tree is divided into arcs. For each arc, the distance to the closest tree of a height within $10 \mathrm{~m}$ of the first is recorded as the gap value. 10 meters is used in this case as an approximation of edge, described by Blennow and Sallnäs [3] as vertical differences in tree height of greater than $10 \mathrm{~m}$. For each run of the model, only the gap values for arcs corresponding to the wind direction are used.

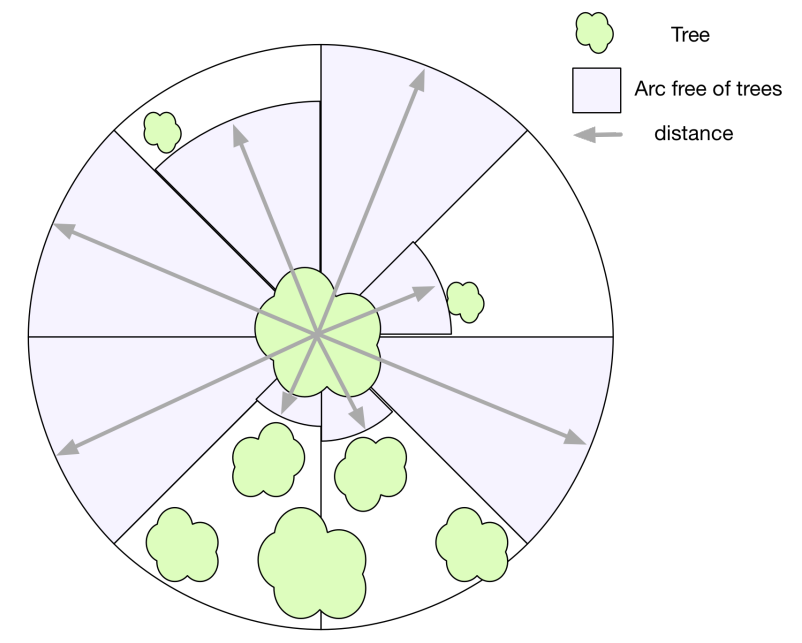

Figure 3: An illustration of the gaprose used in the shielding calculation. The centre tree is considered to be shielding other trees if it is in proximity to and upwind of the other trees.

As the critical wind speed required for stem breakage and uprooting is dependant upon the gap factor, they are also dependant upon wind direction. Additional roses are constructed for each critical wind speed (breakage and uprooting) for every tree. Therefore, at this stage the critical wind speed to cause damage is estimated for every tree, and for every wind direction. 
This can be compared to the values of estimated wind speed and direction discussed in the next section as an indication of risk.

\subsection{Step 3: The Intelligent Scaling of Wind}

This section describes how the framework answers the question "What is the estimated wind speed at each trees location?" Within this model, wind is considered as one of the primary causal factors in tree failure, and the key factor upon which TREEFALL bases risk estimations.

Throughout wind calculations covered in this section, the maximum 3 second gust characteristics are considered. Gardiner et al. [10] argues for the use of maximum gust speed as they more accurately correlate with maximum potential levels of damage: "As mean speeds may not depict the maximum force applied to tree crown ... Gust speed is strongly correlated to the maximum potential levels of damage"[10]. Therefore, TREEFALL uses gust speeds as an estimate of maximum wind speed.

The most suitable, frequently updated and freely available source for maximum gust speed and direction data in the UK is the Met Office DataPoint service. At the time of writing there are over 200 sites collecting various meteorological data (including wind speed and direction measurements) spread out across the UK, accessible via a developer Application Programming Interface (API). The data produced is location specific and therefore some interpolation is required before wind speed and direction can be estimated on an individual tree basis.

To do this, a series of geoprocessing operations are carried out. For wind speeds, simple interpolation between irregularly spaced Met station data points is not appropriate as because these techniques do not consider 
the impact of terrain. To account for this, we use the MIDAS LTA wind speed $5 \mathrm{~km}$ gridded data set which accounts for the large scale terrain variations which influence the general wind patterns. We calculate the differences between the MIDAS monthly long term averages and those from Met station data points. These differences are then interpolated using Inverse Distance Weighting (IDW), and then combined with the long term average gridded data to produce a $5 \mathrm{~km}$ gridded dataset for use in subsequent stages of the analysis. The various stages involved in the downscaling of wind speed are visualised in Figure 4. 


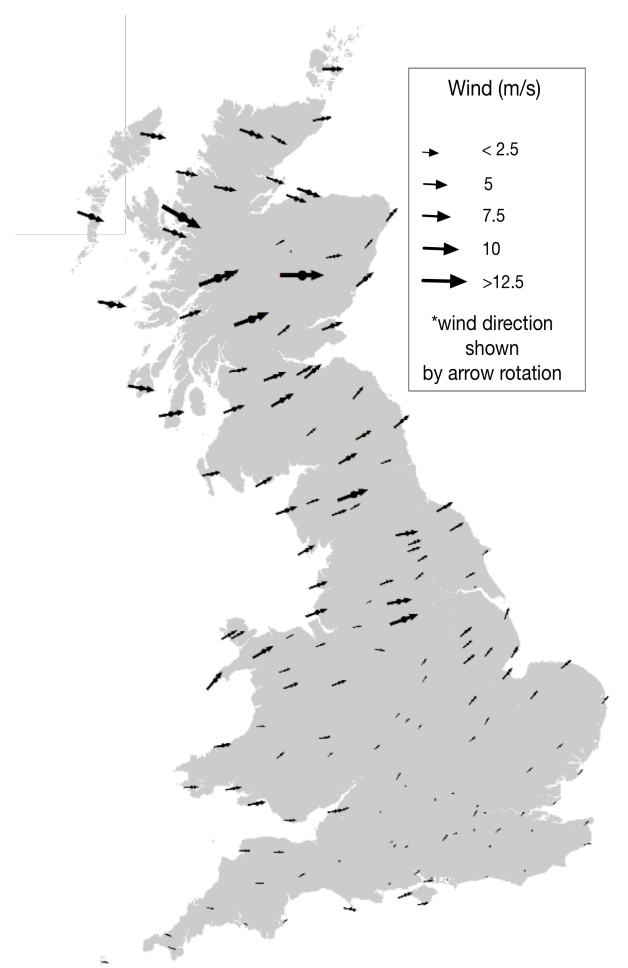

(a) Met Office Gust Speeds.

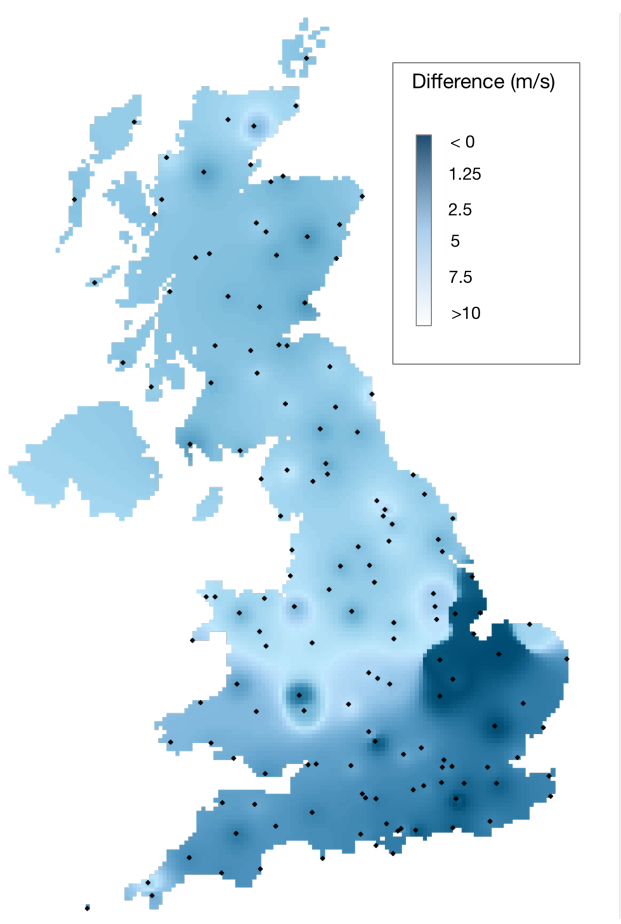

(c) IDW Difference (a) to (b)

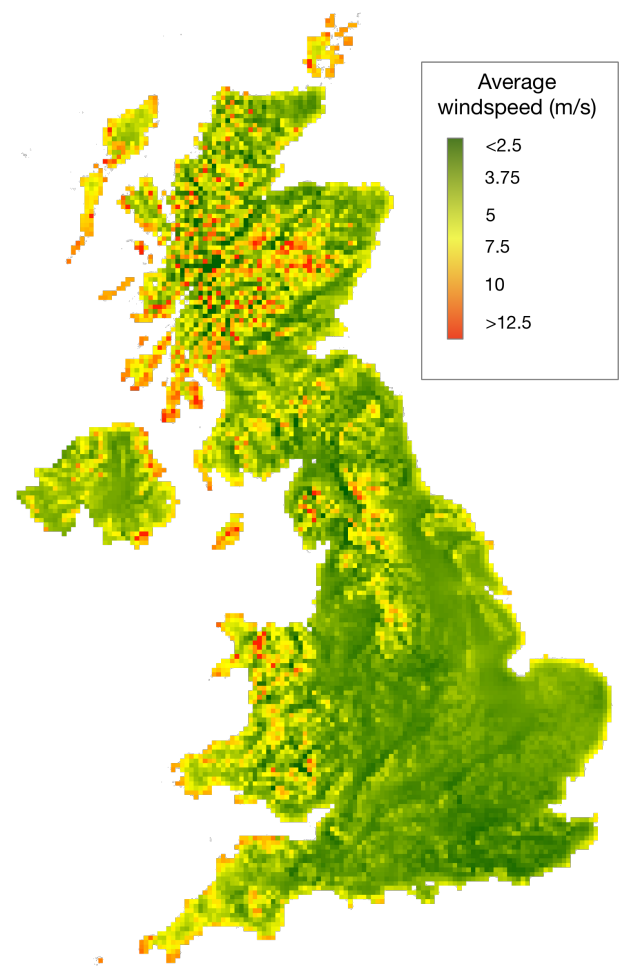

(b) LTA Wind speeds.

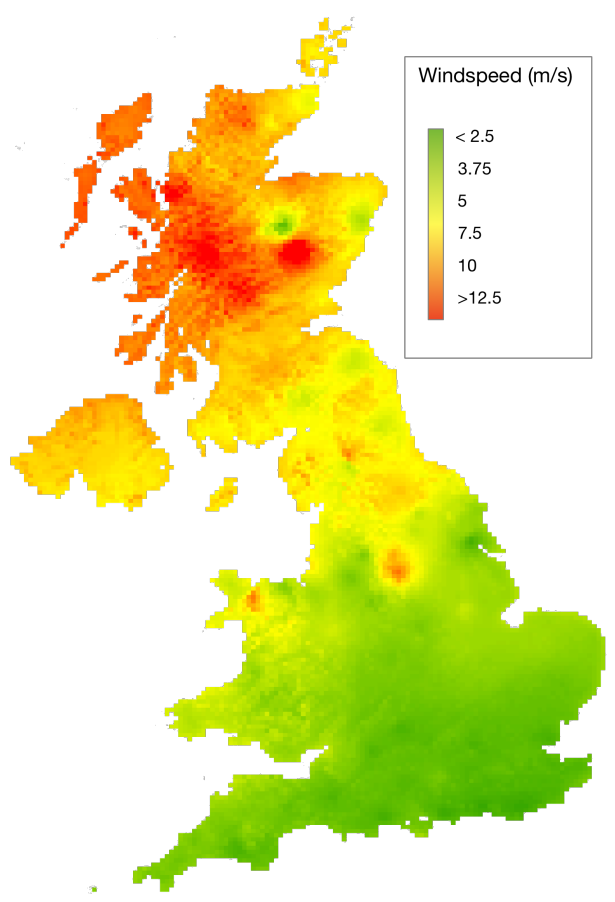

(d) Final Wind Speeds

Figure 4: Visualisation of procedure used to downscale wind speed. 
Similarly, wind direction from the Met data points is decomposed into its vector components $(\mathrm{U}$ and $\mathrm{V})$. Each of these components are individually interpolated using IDW, then the resulting interpolated $\mathrm{U}$ and $\mathrm{V}$ values are recombined back into vectors representing angle in a $5 \mathrm{~km}$ grid. This process is discussed in detail by Schaefer and Doswell III [24].

Finally, each wind speed and wind direction in the $5 \mathrm{~km}$ output is used as an input to the Flowstar component of the Atmospheric Dispersion Modelling System (ADMS) Urban software package. Flowstar also requires a DTM and a surface roughness map for each region which, for the UK is derived from the Centre for Ecology and Hydrology (CEH) LCM, and when run it simulates terrain and wind interaction producing a $10 \mathrm{~m}$ gridded output, with values for multiple heights above ground. The full downscaling process is illustrated in figure 5. 


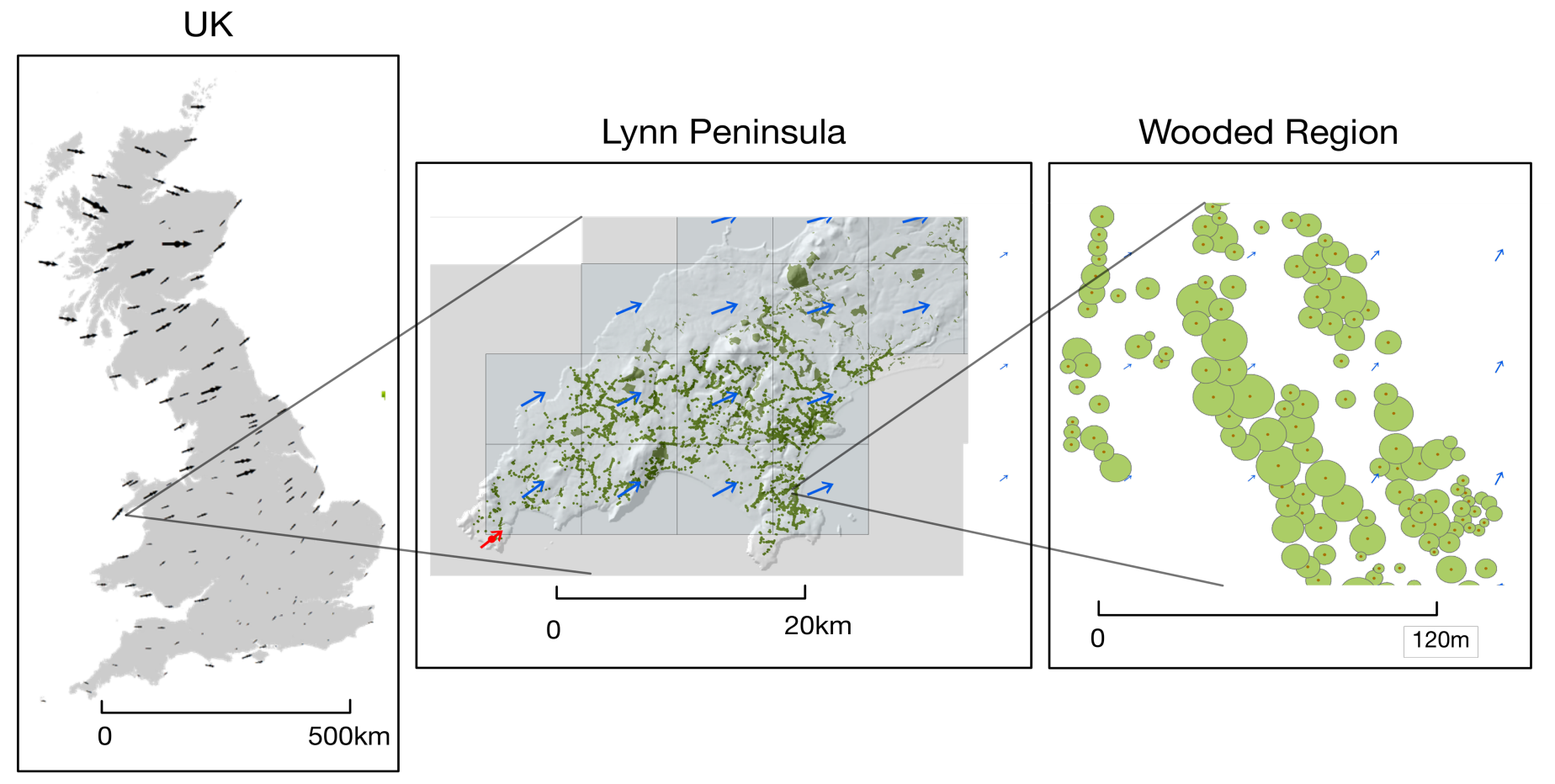

Figure 5: Visualisation of the overall procedure used for downscaling wind speed and direction to the individual tree scale. From left to right: Met office data points with wind vectors; gridded interpolation results (at $5 \mathrm{~km}$ resolution) with station vectors (red) and interpolated result vectors (blue); and Flowstar output (at 40m resolution) where red dots represent crown centre, green circles represent tree canopy, blue arrows represent wind vectors.

Validation of wind speed estimates was achieved through a jackknife analysis of historical weather data collected from MIDAS. The collected data represented 170 weather stations across the UK at 30min resolution. The following process was used a total of 1000 times:

1. Randomly select a 30 minute window between 2010 and 2018 .

2. Randomly select a station (labelled 'target'). 
3. Record target's actual measured wind speed

4. Remove target from dataset.

5. Estimate the wind characteristics at target's location.

6. Compare estimate to target's known values.

The above process yielded an $R^{2}$ and RMSE of 0.68 and $1.4 \mathrm{~m} / \mathrm{s}$ respectively. Without the use of the LTA the $R^{2}$ and RMSE adjusted to 0.52 and $1.8 \mathrm{~m} / \mathrm{s}$ respectively.

This approach it is possible to estimate the wind speed above the crown of each tree, taking into account the characteristics of the terrain. The effective wind speed atop each tree can be estimated by considering the crown height of each tree above the zero-plane displacement (the height at which average wind speed can be considered zero due to shielding of nearby trees) following a similar approach to both ForestGales and iLand. Raupach [20, 19] outlines the relevant calculations in detail. These formulae provide roughness length and zero-plane displacement of vegetated surfaces, as functions of canopy height and area index.

\subsection{Stage 3: Risk Calculations and Proximity Detection}

The final stage of the modelling process is to calculate the level of risk for each tree, addressing the questions: "Is the estimated wind speed greater than the critical wind speed?" and "Can this tree cause damage to nearby Infrastructure?". This is accomplished by comparing the difference between the estimated wind speed at each tree given its position in a stand (section 2.3) with the estimated critical wind speed needed to generate either stem breakage or uprooting (section 2.1) for the appropriate wind direction. This 

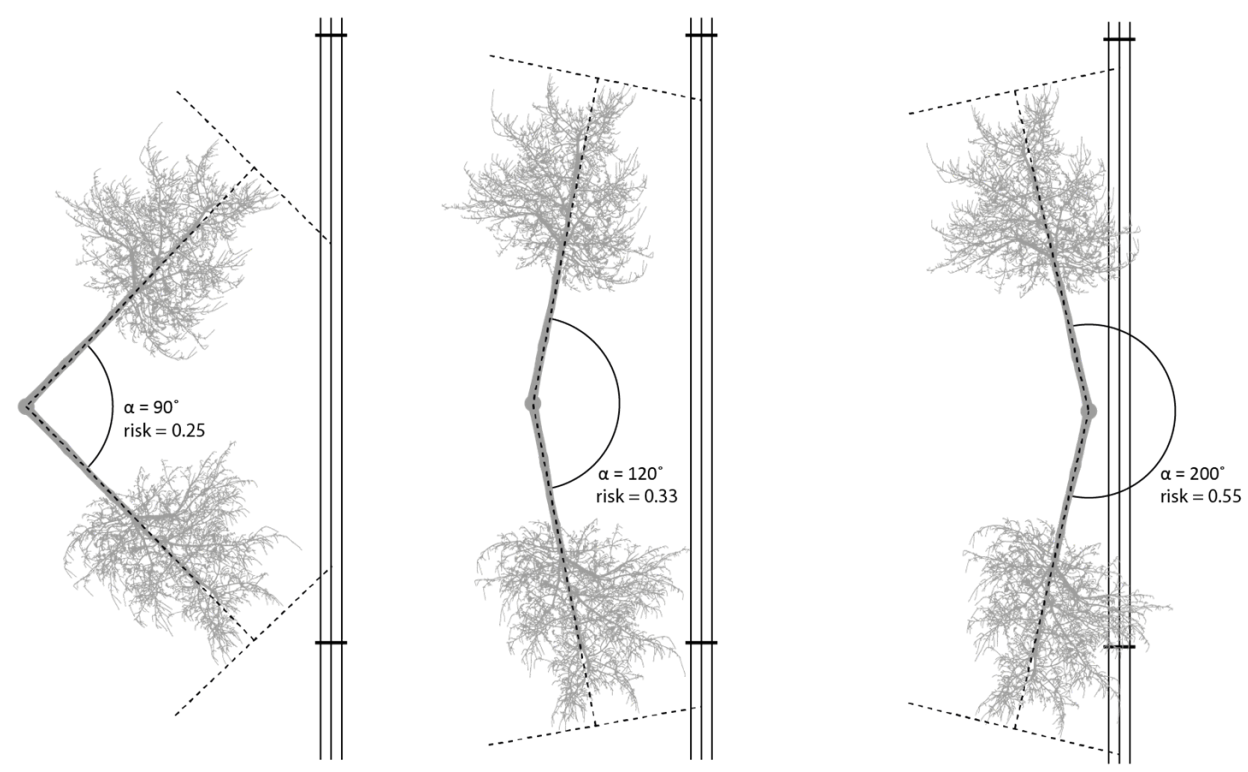

Figure 6: A diagram showing how the Area of Risk is calculated on the horizontal plane. The ratio of directions that a tree can fail in and disrupt infrastructure represents the risk.

risk value is then compounded by the consequences that this failure has upon infrastructure. The closer the tree to this infrastructure, the greater the risk. To compute risk a trigonometric calculation is used in which the tree shape is simplified as a cylinder atop a trunk, with the area this shape can reach as it pivots about its base being identified as the Area of Risk (AoR). The overlap of this AoR and infrastructure in 3D space is calculated as a value from no overlap to total overlap ( 0.0 to 1.0 respectively). These two risk values (risk to turning, and risk to infrastructure) combine to produce a value for overall risk. Figures 6 and 7 show this process from the horizontal and vertical viewpoints of this calculation with respect to a power line. 


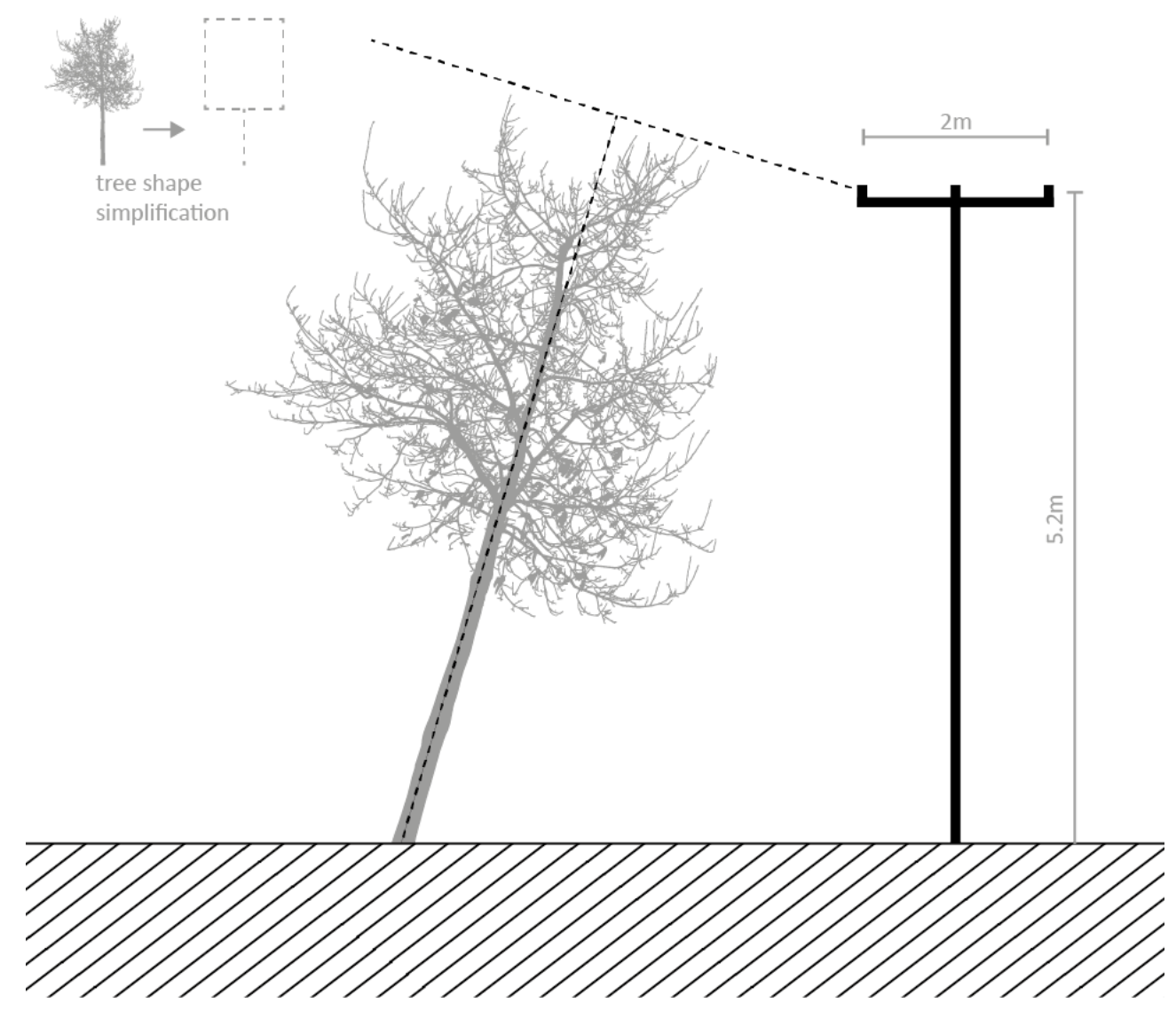

Figure 7: A diagram showing how the Area of Risk is calculated on the vertical plane. The ratio of directions that a tree can fail in and disrupt infrastructure represents the risk. 


\section{The Interface, Example uses and Discussion}

The TREEFALL model is designed to fulfil two roles: firstly to act ahead of time with predicted weather data as part of an infrastructure damage prevention scheme; and secondly as part of a scenario work flow, working with hypothetical weather as part of targeted maintenance. It can be used to investigate a wide variety of topics and scenarios; wind speed, angle, shielding, elevation, and risk distribution. Figure 8 shows an area of trees in southern England when subjected to a hypothetical, yet typical [13] south westerly wind with maximum gust speeds of $20 \mathrm{~m} / \mathrm{s}$ on the left, and a less typical south easterly wind gusting at $20 \mathrm{~m} / \mathrm{s}$ on the right. Each tree, represented by a circle, is coloured depending on its relative aerodynamic stresses (green $=$ low, yellow $=$ medium, red $=$ high $)$. Those trees at the edge of the stand, and those which are facing the direction of the incoming wind are logically experiencing higher levels of aerodynamic stress. Similarly, this edge is slowing the wind, lowering the stress experienced by trees deeper in the canopy. Aerodynamic stresses can be seen to increase where trees are taller than the average height of the canopy. These trees are emerging from the canopy, and as such, their height above the zero-place displacement height is increasing and they are therefore less shielded from the force of the wind. 


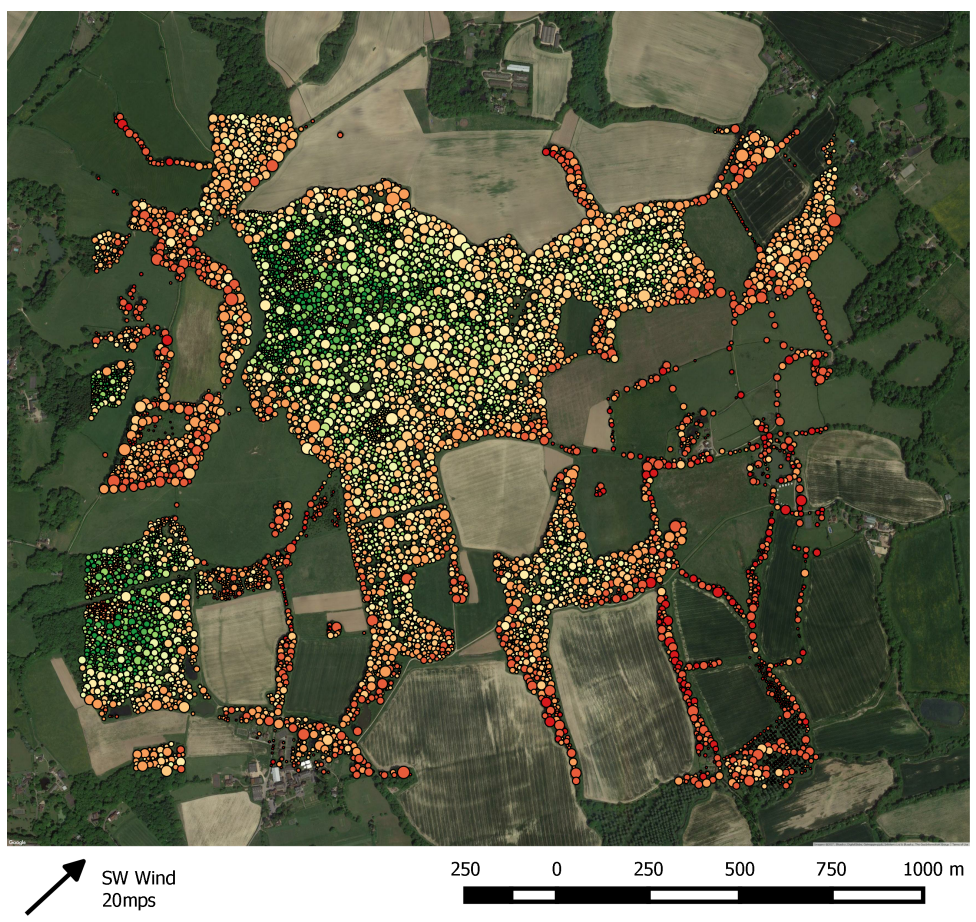

(a) $20 \mathrm{~m} / \mathrm{s}$ SW wind.

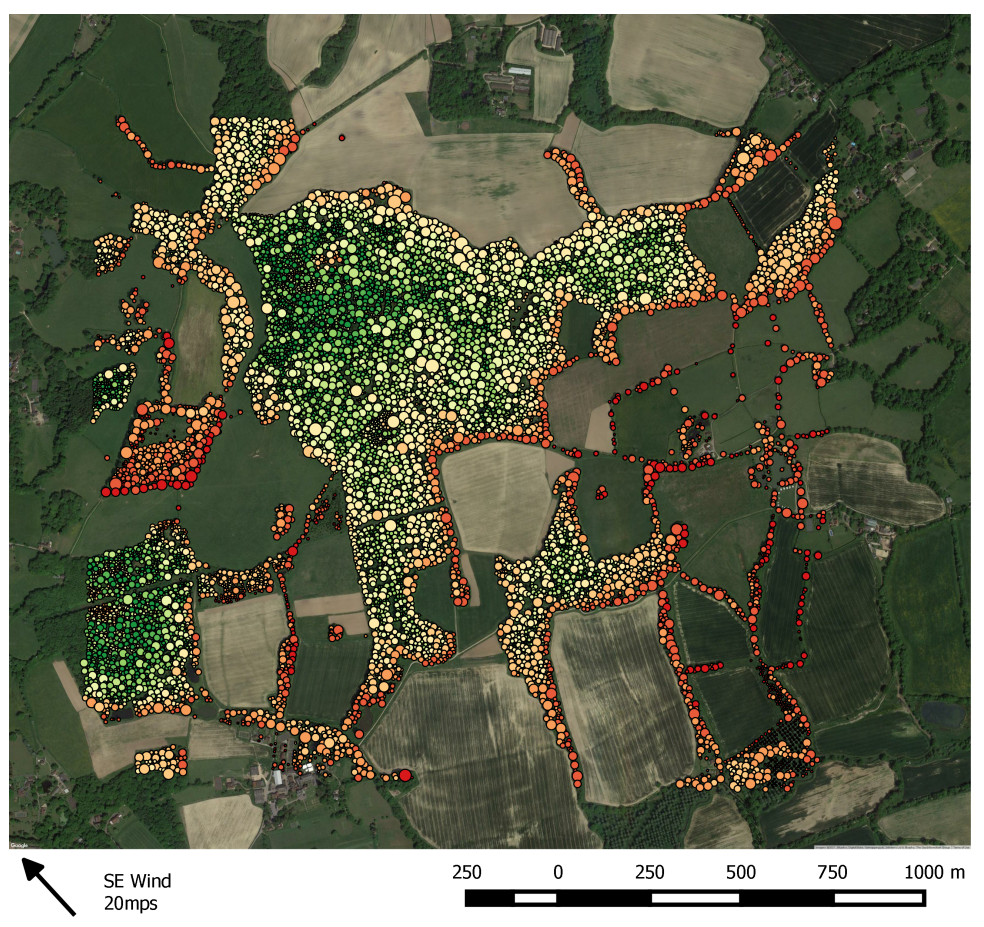

(b) $20 \mathrm{~m} / \mathrm{s}$ SE wind.

Figure 8: Stand experiencing winds for different directions. Red indicates high relative aerodynamic stresses, yellow indicates medium, and green indicates low. Here only aerodynamic stresses are shown, not risk to nearby infrastructure. 
Whilst output such as that shown in Figure 8 is useful to gain an overall understanding of the location of risky trees, this model is targeted at analysis of risk to infrastructure. To accommodate this, the web interface allows users to upload an infrastructure dataset and specify either predicted weather, past observed weather, or construct a hypothetical dataset of wind speeds and direction. Following this, the web interface allows the exploration of all previously discussed datasets (trees, wind, land, and infrastructure network), and view relative risks following a 'traffic light' colour code: red for high relative risk, and near infrastructure; orange for medium risk, but cannot hit infrastructure; and green for low risk. Similarly, the 'in-danger' sections of infrastructure are coloured red to indicate risk. The interface and outputs are illustrated in Figure 9. 


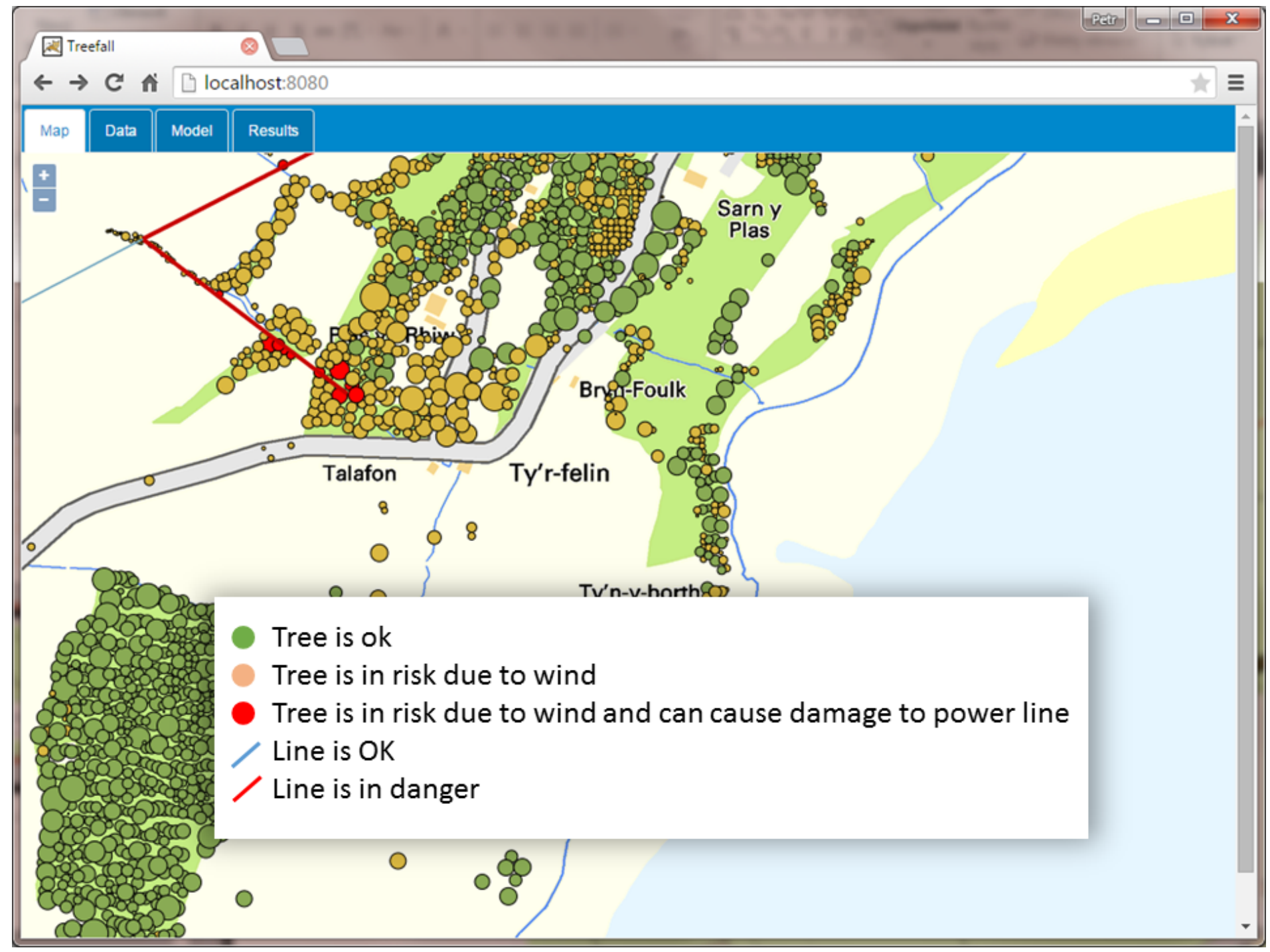

Figure 9: A screenshot of TREEFALL showing web interface, and traffic light risk colouring. Here, powerlines at risk can been seen in red, with those trees posing risk also coloured red. Trees posing less risk are coloured yellow and green.

As an example of the use of TREEFALL over a large area, Figure 10 shows a study site in north Wales that covers part of the electricity distribution 
network operated by Scottish Power. For this area, a dataset of power lines has been loaded into TREEFALL and a southerly wind of $20 \mathrm{~m} / \mathrm{s}$ has been specified. There are millions of trees in proximity of the power network which need to be monitored and potentially managed by Scottish Power. Using the outputs from TREEFALL, segments of power lines have been coloured by the number of risky trees in proximity to the line, a way of identifying segments that can be prioritised for further investigation.

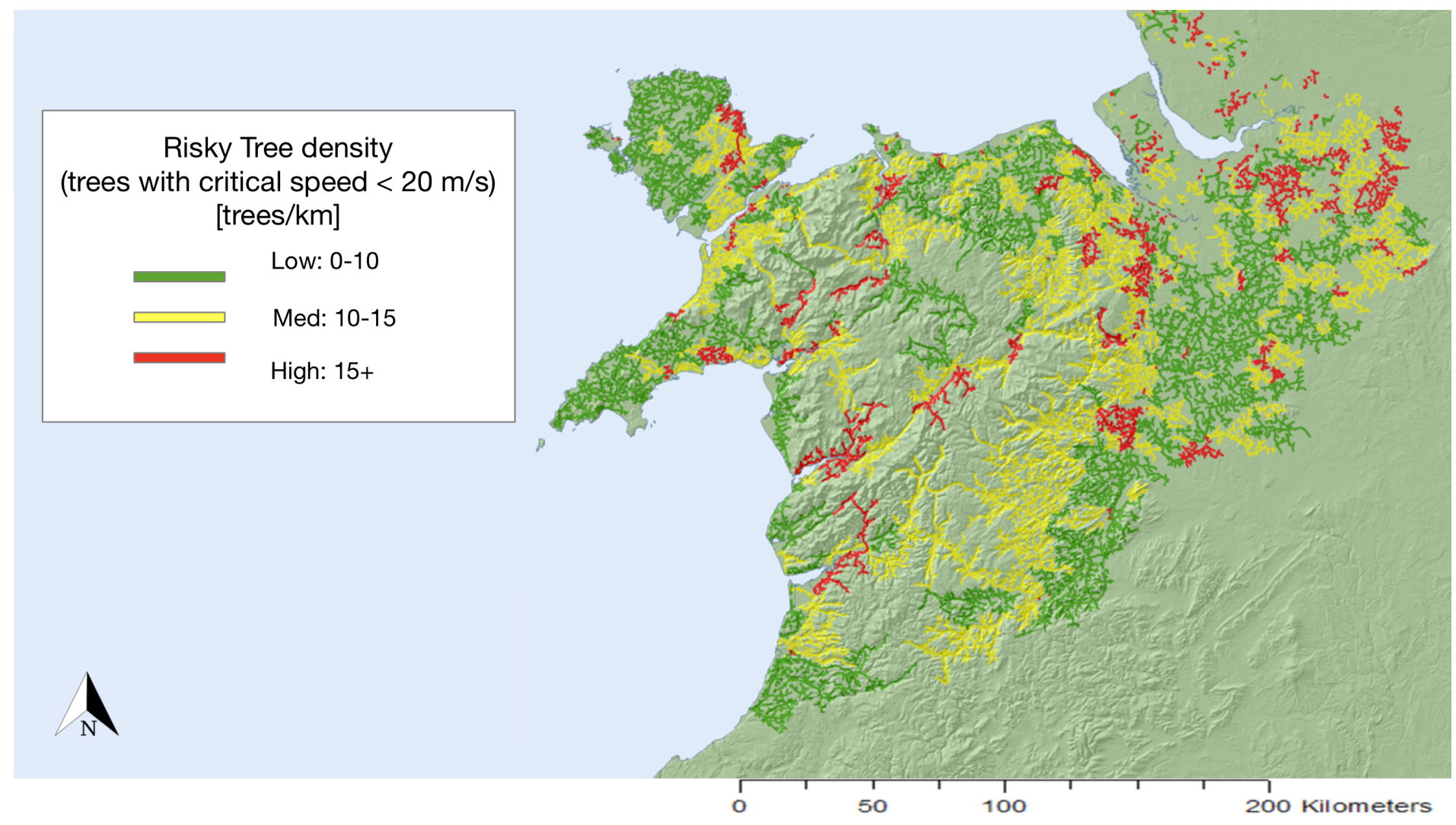

Figure 10: A power line network coloured by density of nearby trees that pose risk to the network in the case of failure. Sections of the network at higher risk are coloured in red, medium in yellow and low in green. 
In addition to the online interface, the risk data can also be exported in a number of common formats so that further analysis is possible in various GIS. For example, further analysis may include the weighting of network features by importance (e.g. by number of homes supplied by each power line). In this way high risk areas that are at critical locations for securing the most important areas of a network can be identified. While TREEFALL calculates risk on a per-tree basis, many applications of the model aggregate these individual tree risks into areas, as shown in Figure 10. When aggregated, areas where it is anticipated that trees are most predisposed to failure can be identified. Trees in these areas are not necessarily facing imminent failure, but they are positioned and sized in such a way that the wind has increased potential to cause failure. Given the challenges of managing the many millions of trees in proximity to infrastructure networks, the outputs of TREEFALL provide a means of spatially targeting areas for field-based tree surveys.

It could be argued that an experienced surveyor could use traditional GIS techniques, such as overlaying infrastructure maps on maps of tree stands, to highlight risk areas to gain equal insight into areas of high risk. However, this results in large areas in which trees are within proximity to the infrastructure. It does not offer insight into the tree properties, or within stand mechanics that may affect prioritisation decisions. This approach arguably leads to the practice of line clearance, where all trees within a specified proximity to the infrastructure are removed. Whilst line clearance does technically offer a network wide solution to the problem of windthrow failure, it can result in the unnecessary removal of trees which has considerable economic, logistical 
and environmental disadvantages. TREEFALL extends the stand based prioritisation approach by offering extra information regarding the trees and between tree interactions that may help further prioritise the task of tree surveillance. The risk posed to nearby infrastructure by trees throughout the stand is not equal: trees with properties that are not conducive to withstanding high winds, those in high wind areas, those unshielded by other trees or those nearer infrastructure offer more risk than others.

To demonstrate the effectiveness of TREEFALL, TREEFALL was compared it to a stand based risk assessment approach. Bíl et al. [2] demonstrated that rail lines surrounded by woodland on both sides within $50 \mathrm{~m}$ are at greatest risk from tree failure. This principle was used to assess the risks of tree failure on the rail network in Great Britain (GB). This was achieved by buffering the entire rail network on each side by $50 \mathrm{~m}$ using simple GIS techniques, and combined with land cover data to identify the types of land cover within $50 \mathrm{~m}$ of the railway line. Sections of line with woodland on one side are considered moderately risky, whereas sections with woodland on both sides of the line are considered at the most risk. The analysis showed that $17 \%(\sim 2750 \mathrm{~km})$ of the GB rail network can be considered moderately risky, and 12\% ( 2000km) can be considered at the highest risk. With such a large distance potentially requiring tree management, further prioritisation is needed.

The outputs from the stand based method and TREEFALL are shown in figures 11 and 12 for a small area of rail network in southern England. The stand based technique (Fig 11) suggests that almost the whole length of line in the study area is at equally high risk from tree failure as the whole length is 
within close proximity to trees on either side. However, TREEFALL outputs (Fig 12) suggest that only a small proportion of the line is susceptible to a high risk of windthrow failure. While 2462 trees are within 50m of the line, and therefore present a theoretical risk to the infrastructure, TREEFALL output indicates that only 484 trees could reach the line in a windthrow event due to their location and size; of these 29 are considered high risk due to their exposure to local wind environment and lack of shielding. These trees can therefore, be prioritised for field investigations and remedial action if necessary. 


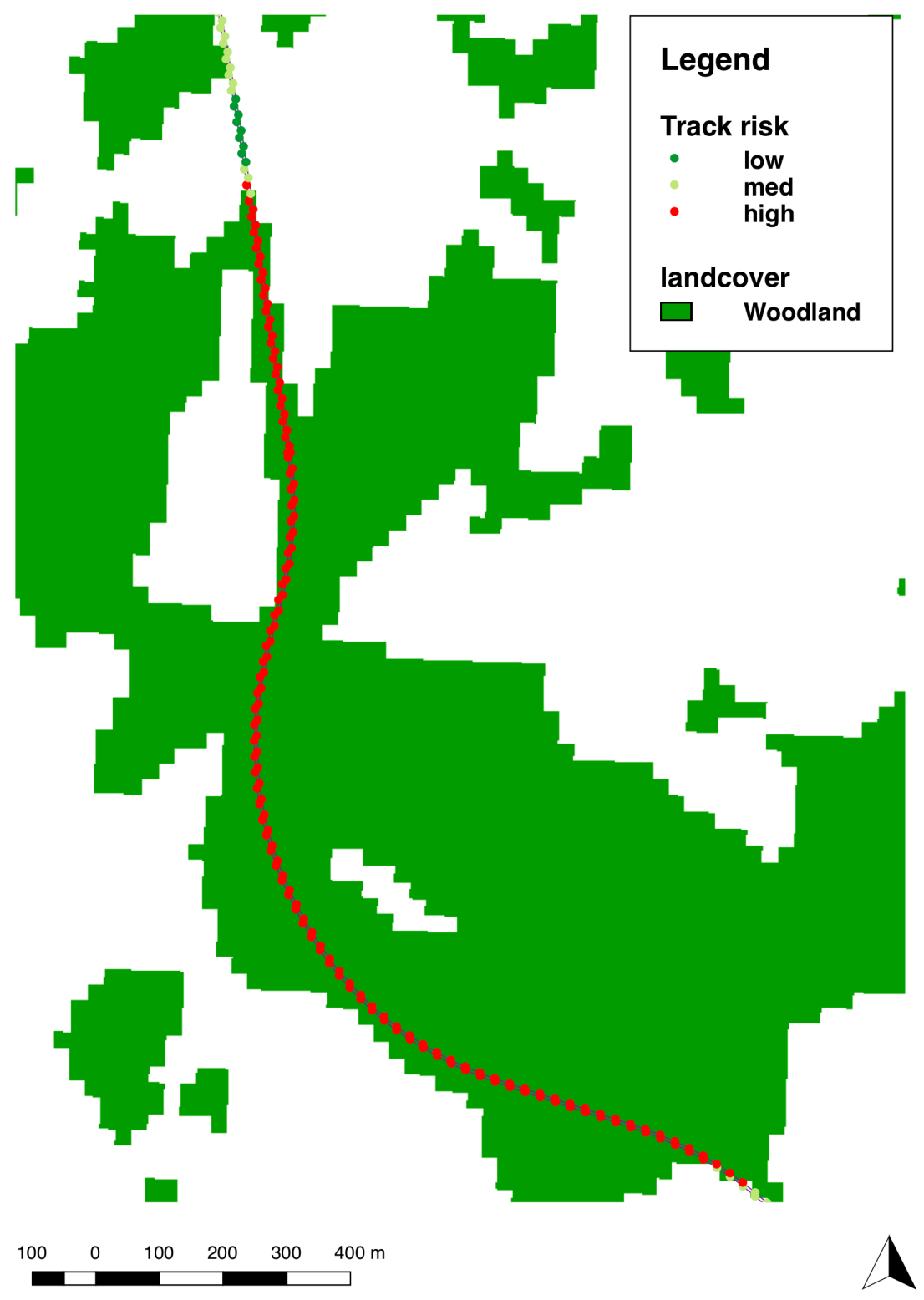

Figure 11: Proximal Trees to rail network in southern England. Stand/landcover based risk output based upon the classification of Bíl et al. [2]. Not that the risk is along the whole length of line passing through the woodland area. 


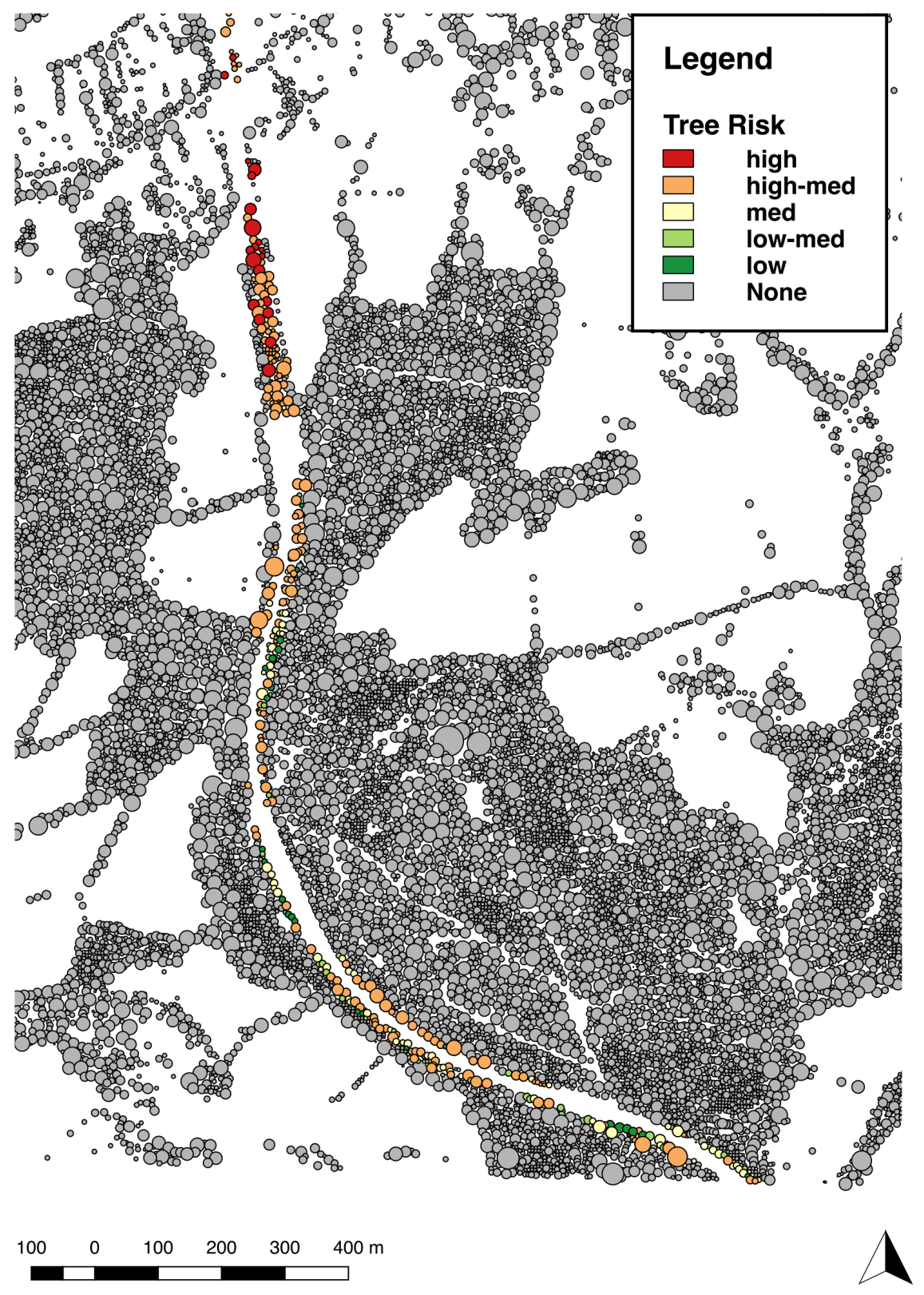

Figure 12: Proximal Trees to rail network in southern England. Risk output from TREEFALL. As can be seen here there is a shift in density of risk to the north of the image. 
It is envisaged that TREEFALL will be used as tool incorporated into the workflow of field operatives. TREEFALL could be used as part of the decision making process when prioritising field surveys. The surveyors would collect data on individual trees related to range of features described in Table 1 which potentially influence failure risk, and feed back in to TREEFALL to adjust the parameters that control the level of failure risk. Repeated surveys of high risk trees could provide a dynamic assessment of the threat to infrastructure and requirements for interventions.

In its current form TREEFALL operates as a mechanistic model for tree failure, offering relative risk outputs for trees and infrastructure in a study area. One of the key drivers of this research is helping operators of infrastructure networks make informed decisions regarding tree management, as such a more probabilistic output may be desired. Whilst probabilistic risk distributions can be determined in TREEFALL's current state, for example by sampling from a known windspeed distribution as input scenarios and collating the output data, this has yet to be implemented in the model.

\section{Conclusion}

The TREEFALL model offers a unique way of quantifying the risk to infrastructure posed by potential tree failures. It does this in an objective and repeatable way on a per-tree basis using a number of well-established models and regression formulae. It takes into account shielding effects within the canopy and is built with the aim of being used repeatedly for large numbers of trees. The user interface permits the use of historical weather data (e.g. for modelling previous damaging storm events), weather forecasts and scen- 
arios and the outputs can be visualised and spatially aggregated according to the requirements of the user. The outputs of TREEFALL identify individual trees which present the greatest risk to nearby infrastructure. These trees can therefore be prioritised for field surveying and remedial action proposed if required. Optimisation of this process permits the most efficient use of field operatives and resources and therefore, maximises the resilience of the network. There is scope for further development of TREEFALL, for example, by incorporating additional variables such as soil information or additional processes such as cascading tree failure. Nevertheless, the current implementation of the model holds considerable potential for informing the management of trees adjacent to utility and transport networks as well as in arboricultural, forestry and environmental research.

\section{Acknowledgements}

We would like to thank the Natural Environment Research Council (NERC) for funding this research, and extend our gratitude to our industrial partners. This work was funded in part by NERC projects NE/M008614/1 and $\mathrm{NE} / \mathrm{N} 012984 / 1$.

\section{References}

[1] Philippe Ancelin, Benoît Courbaud, and Thierry Fourcaud. Development of an individual tree-based mechanical model to predict wind damage within forest stands. Forest ecology and management, 203(1): 101-121, 2004. 
[2] Michal Bíl, Richard Andrášik, Vojtěch Nezval, and Martina Bílová. Identifying locations along railway networks with the highest tree fall hazard. Applied geography, 87:45-53, 2017.

[3] Kristina Blennow and Ola Sallnäs. Windaa system of models for assessing the probability of wind damage to forest stands within a landscape. Ecological modelling, 175(1):87-99, 2004.

[4] GM Bonnor. Stem diameter estimates from crown width and tree height. The Commonwealth Forestry Review, pages 8-13, 1968.

[5] Antoine Colin, Céline Meredieu, Thierry Labbé, Thierry Belouard, and Sylvie Batifol. Étude rétrospective et mise à jour de la ressource en pin maritime du massif des landes de gascogne après la tempête klaus du 24 janvier 2009. 2010.

[6] Paul M Della-Marta and Joaquim G Pinto. Statistical uncertainty of changes in winter storms over the north atlantic and europe in an ensemble of transient climate simulations. Geophysical Research Letters, 36(14), 2009.

[7] Barry Gardiner, Heli Peltola, and Seppo Kellomäki. Comparison of two models for predicting the critical wind speeds required to damage coniferous trees. Ecological modelling, 129(1):1-23, 2000.

[8] Barry Gardiner, Ken Byrne, Sophie Hale, Kana Kamimura, Stephen J Mitchell, Heli Peltola, and Jean-Claude Ruel. A review of mechanistic modelling of wind damage risk to forests. Forestry, 81(3):447-463, 2008. 
[9] Barry Gardiner, Ken Byrne, Sophie Hale, Kana Kamimura, Stephen J. Mitchell, Heli Peltola, and Jean-Claude Ruel. A review of mechanistic modelling of wind damage risk to forests. Forestry: An International Journal of Forest Research, 81(3):447, 2008. doi: 10.1093/forestry/ cpn022.

[10] Barry Gardiner, Kristina Blennow, Jean-Michel Carnus, Peter Fleischer, Frederik Ingemarson, Guy Landmann, Marcus Lindner, Mariella Marzano, Bruce Nicoll, Christophe Orazio, et al. Destructive storms in european forests: past and forthcoming impacts. Destructive storms in European forests: past and forthcoming impacts., 2010.

[11] Frank Hegyi. A simulation model for managing jack-pine stands. Growth models for tree and stand simulation, 30:74-90, 1974.

[12] Gary W Hickman, E Perry, and Richard Evans. Validation of a tree failure evaluation system. Journal of Arboriculture, 21:233-233, 1995.

[13] Alan Lapworth and James McGregor. Seasonal variation of the prevailing wind direction in britain. Weather, 63(12):365-368, 2008.

[14] Nelda Matheny and Jim Clark. Tree risk assessment. Arborist News, 19 (1):28-33, 2009 .

[15] C Mattheck, K Bethge, and PW West. Breakage of hollow tree stems. Trees, 9(1):47-50, 1994.

[16] Jon Murray, George Alan Blackburn, James Duncan Whyatt, and Christopher Edwards. Using fractal analysis of crown images to measure the 
structural condition of trees. Forestry: An International Journal of Forest Research, 2018.

[17] H. Peltola, S. Kellomäki, H. Väisänen, and V.-P. Ikonen. A mechanistic model for assessing the risk of wind and snow damage to single trees and stands of scots pine, norway spruce, and birch. Canadian Journal of Forest Research, 29(6):647-661, 1999.

[18] Heli M Peltola. Mechanical stability of trees under static loads. American Journal of Botany, 93(10):1501-1511, 2006.

[19] M_R Raupach. Drag and drag partition on rough surfaces. BoundaryLayer Meteorology, 60(4):375-395, 1992.

[20] MR Raupach. Simplified expressions for vegetation roughness length and zero-plane displacement as functions of canopy height and area index. Boundary-Layer Meteorology, 71(1):211-216, 1994.

[21] Horst WJ Rittel and Melvin M Webber. Dilemmas in a general theory of planning. Policy sciences, 4(2):155-169, 1973.

[22] CJ Rooney, HDP Ryan, DV Bloniarz, and BCP Kane. The reliability of a windshield survey to locate hazards in roadside trees. Journal of Arboriculture, 31(2):89-94, 2005.

[23] Luigi Sambuelli, Laura Valentina Socco, Alberto Godio, Giovanni Nicolotti, and Roberto Martinis. Ultrasonic, electric and radar measurements for living trees assessment. Bollettino di Geofisica Teorica ed Applicata (Bulletin of Theoretical and Applied Geophysicist), 44:3-4, 2003. 
[24] Joseph T Schaefer and Charles A Doswell III. On the interpolation of a vector field. Monthly Weather Review, 107(4):458-476, 1979.

[25] Rupert Seidl, Werner Rammer, Robert M Scheller, and Thomas A Spies. An individual-based process model to simulate landscape-scale forest ecosystem dynamics. Ecological Modelling, 231:87-100, 2012.

[26] Rupert Seidl, Werner Rammer, and Kristina Blennow. Simulating wind disturbance impacts on forest landscapes: tree-level heterogeneity matters. Environmental modelling \& software, 51:1-11, 2014.

[27] Guenter Sinn and Lothar Wessolly. A contribution to the proper assessment of the strength and stability of trees. Arboricultural Journal, 13 (1):45-65, 1989.

[28] LV Socco, Luigi Sambuelli, R Martinis, Elena Comino, and G Nicolotti. Feasibility of ultrasonic tomography for nondestructive testing of decay on living trees. Research in Nondestructive Evaluation, 15(1):31-54, 2004.

[29] YOSHIRO Tomikawa, Yukiharu Iwase, Kishino Arita, and Hiroaki Yamada. Nondestructive inspection of a wooden pole using ultrasonic computed tomography. IEEE transactions on ultrasonics, ferroelectrics, and frequency control, 33(4):354-358, 1986.

[30] X Wang, J Wiedenbeck, RJ Ross, JW Forsman, JR Erickson, C Pilon, and BK Brashaw. Nondestructive evaluation of incipient decay in hardwood logs. res. pap. Technical report, FPL-GTR-162. WI: US De- 
partment of Agriculture, Forest Service, Forest Products Laboratory, 2005.

[31] L Wessolly. Fracture diagnosis of trees part 2: Statics-integrated methods-statically-integrated assessment (sia). Stadt und Grün, 8:570$573,1995$.

[32] Lothar Wessolly and Martin Erb. Handbuch der Baumstatik+ Baumkontrolle. Patzer, 1998.

[33] Philip W West and Philip W West. Tree and forest measurement, volume 20. Springer, 2009.

[34] Hongcheng Zeng, Ari Talkkari, Heli Peltola, and Seppo Kellomäki. A gis-based decision support system for risk assessment of wind damage in forest management. Environmental Modelling \&3 Software, 22(9):12401249, 2007. 